\title{
Obituary: Shayne Martin Jacobs (20th April 1971-19th September 2021)
}

\author{
Neil E. Pettit • Neal J. Enright · Karen J. Esler • \\ Will Stock $\cdot$ Robert J. Naiman
}

Published online: 17 February 2022

(C) The Author(s), under exclusive licence to Springer Nature B.V. 2022

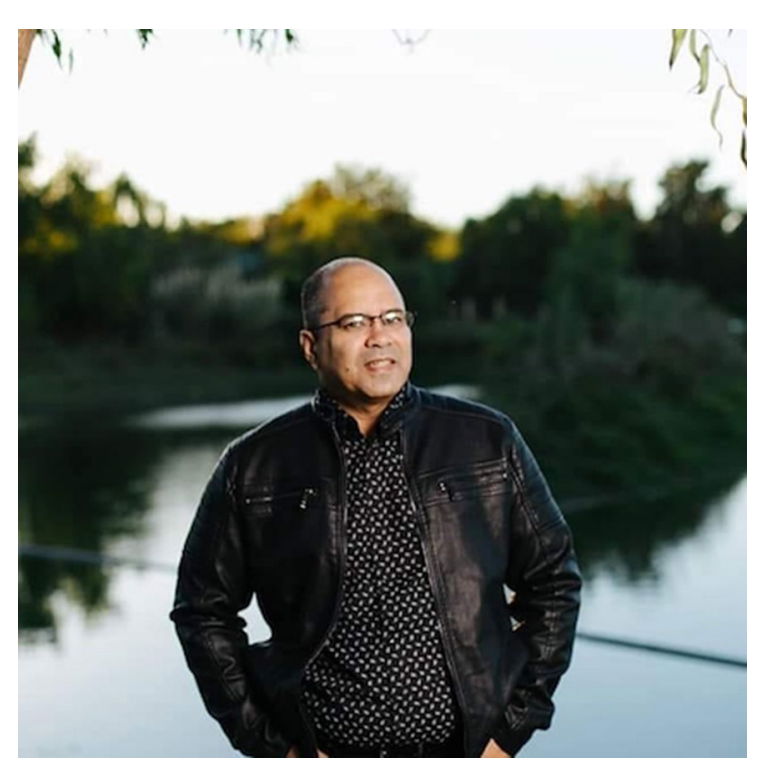

Shayne Jacobs, Stellenbosch, 2018

N. E. Pettit · W. Stock

Edith Cowan University, Joondalup, WA, Australia

N. J. Enright $(\bowtie)$

Plant Ecology, and Emeritus Professor, Murdoch

University, Perth, WA, Australia

e-mail: N.Enright@murdoch.edu.au

\section{K. J. Esler}

Conservation Ecology \& Entomology, Stellenbosch

University, Stellenbosch, South Africa

\section{R. J. Naiman}

University of Washington, Seattle, USA
It is with great sadness that we mourn the death of Shayne Martin Jacobs, in September 2021, related to complications arising from contracting the COVID19 virus. Struck down in the prime of his life and in the midst of a flourishing career Shayne will be greatly missed, as an esteemed colleague, and husband, father and grandfather to his loving family, and friends. Shayne was an Associate Professor at the Department of Conservation Ecology and Entomology for Stellenbosch University, South Africa. Shayne acted as an Associate Editor for this Journal from August 2011 to September 2021, handling the review of, and decision for, 36 manuscripts. He also acted as a reviewer for a further nine manuscripts for

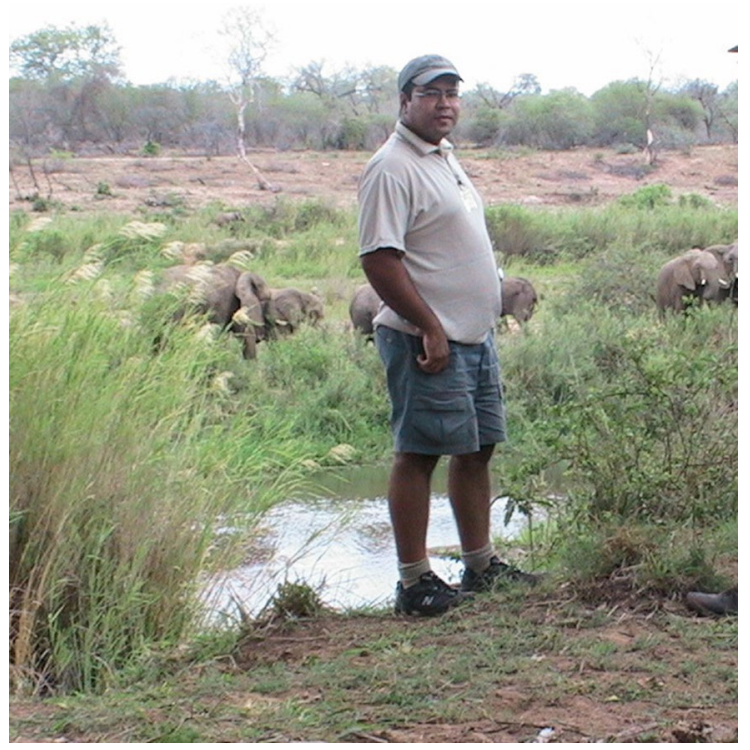

Shayne Jacobs, Kruger National Park, 2003 
the journal over this time period. He was a pro-active and highly regarded member of the Plant Ecology editorial team.

Shayne's principal interest in science was in the field of conservation ecology and community engagement with a particular focus on nutrient and plant-soil-water-interactions, viewed through a lens of plant physiological ecology and ecosystems ecology. Shayne's philosophy for ecology was based on trying to understand underlying phenomena (mechanisms) and using this knowledge for the restoration of ecosystems (application). His focus on ecosystem regeneration was not only as an end in itself, but also a means for enhancing livelihoods of the poorest in South African and African contexts. This was his ultimate goal for a career in ecology; systems ecology with purpose. He always was of the view that research must inform the restoration and management of landscapes in partnership with conservation agencies and the community, and must also enhance livelihoods of poor rural communities.

Shayne's early life provided a solid foundation for his career in science and the important role for science in the wider community. Shayne grew up in the family home in Haarlem, a mission-station town in the Langkloof, Western Cape. Growing up in this small church community, that retained its social connections through apartheid, provided him with a solid foundation that played a significant role in producing leaders such as Shayne in many realms of society, including science.

Shayne's journey in science began at Pacaltsdorp High School at George in the Western Cape. He then went to the University of Stellenbosch to study a BSc which he completed with Honours, Cum Laude in 1992. This was followed by a research MSc investigating the role of abscisic acid in determining the drought tolerance of spring wheat cultivars in the Western Cape of South Africa. This was completed at Stellenbosch University in 1995 under the supervision of Prof $\mathrm{O} \mathrm{T}$ de Villers with support and guidance from Dr G A Agenbag. This work, together with the links and connections made, were critical for Shayne to undertake independent research and lead to his $\mathrm{PhD}$ studies which he undertook at the University of Cape Town under the supervision of Professor William Stock. His studies were sponsored by the FORESTEK division of the Council for Industrial Research (CSIR) where he spent time based in their offices in Stellenbosch, Nelspruit and Durban. He tackled a problem of global importance which was of concern in South Africa at the time which was the impact of emissions on plantation and native ecosystems, particularly nitrogen, from numerous power plants located in the Mpumalanga region. His research required field and laboratory experiments to determine the effects of the power plant emissions. During his PhD studies he was awarded a British Council grant which afforded him the opportunity to visit the UK and Europe to meet scientists with similar interests including attending the 'First International Nitrogen Conference' held in The Netherlands in 1998. Interacting with international scientists was a stimulus for Shayne to seek other opportunities to think global but contribute local, something he was always passionate about.

From 2002 to 2005 Shane was Post-Doctoral Associate, School of Fishery Sciences, University of Washington, Seattle, Washington, USA, with Professor Bob Naiman, working on the Sabie River at Skukuza in Kruger National Park, South Africa. Bob Naiman considers himself fortunate to have worked with Shayne as part of the University of Washington (UW) team. Shayne joined UW as a young scientist, beginning his academic journey in the optimism of the post-apartheid era in South Africa. For several years - before joining Stellenbosch University - Shayne was an anchor for the UW research projects in Kruger National Park (KNP). His field work in Kruger was physically demanding and the lab facilities were rudimentary, yet his research was exemplary. During his few years in Kruger he also assisted with the construction of exclosures for large animals to investigate the effects of herbivory on plants and soils and organized an international workshop with some of the world's most respected scientists on nutrient cycling in savannas (Ecosystems 10:1231-1249 [2007]). He was the lead author on three publications from his research in Kruger, and a co-author on three others. Whilst working at Kruger, Shayne gave freely of his time to help others, especially students and technicians, and treated everyone with respect. Bob Naiman remembers fondly Shayne's visit to Bob's home in Seattle and Friday Harbor (Washington) where he caught salmon and helped with the building of Bob and his wife's new home.

As a co-researcher for UW Neil Pettit worked with Shayne for 5 years in Kruger NP (2002-2007). Neil 
recalls: When I was visiting Kruger for field work, Shayne very kindly invited me to stay with him at the N'waswitshaka research camp at Skukuza. I liked Shayne a lot; he was a good man and a good colleague and I always enjoyed his company. Shayne could be a very funny man and we always enjoyed a good laugh and shared a cold beer after our long days of fieldwork, which more often than not lead to long discussions about ecology. Shayne and I helped each other with field work, and in the rudimentary laboratory that Shayne set up in the vet building at Skukuza, and we benefitted greatly from numerous discussions on specific and philosophical aspects on ecology, science and also broader social and political issues. During my time in Kruger I received a great education from Shayne on the past and present state of South African politics. Shayne came to stay with my family in Perth, Western Australia, and we had a wonderful week touring throughout the south west. Shayne was particularly keen to see some kangaroos.

In January 2006 Shayne was appointed to the Department of Conservation Ecology \& Entomology as a senior lecturer and in 2018 as Associate Professor. Shayne taught units in Biome Ecology and Conserving Nature as well as MSc units in sustainable agriculture. Shayne's teaching philosophy was based around giving students opportunities to prepare themselves for a career where diversity of cultures, cultural sensitivity, a broadminded approach to beliefs as pertaining to conservation, and understanding of the role of coloniality in conservation, will play a significant role in the success of conservation efforts. Shayne believed that when students complete their studies they are ready to apply knowledge, be culturally sensitive, broad-minded, adaptable, innovative and values-driven.

Shayne's research interests were diverse and included Ecosystems Ecology; Conservation Ecology; Restoration Ecology; Regenerative Agriculture and Innovation and Entrepreneurship applied to Agroecological systems. Shayne was well published in the international science literature. He authored 55 journal publications with 933 citations and a research $\mathrm{H}$ index of 14 . Shayne was very keen to teach and nurture new scientists and was a supervisor of $6 \mathrm{com}$ pleted and 7 current PhD students as well as 22 completed MSc students.

Shayne was also diligent in contributing to the broader university community and served on various University Committees including the Timetabling and Social Impact Committees for the AgriScience Faculty at Stellenbosch University. As a service to the agricultural sector, Shayne was the co-founder, along with colleague Prof. Karin Jacobs (not related), of a company called Sporatec, a microbiology laboratory that specializes in soil microbiology.

The most important motivation for Shayne's career in science was enhancing the knowledge economy (diverse types of knowledge, perspective and approaches to knowledge generation), especially as pertaining to South Africa and Africa. For Shayne this meant a commitment and strong involvement in training and mentorship of young Black, Coloured and Indian scientists (diversity of cultures, perspectives and approaches) to enhance and support the economy, and work towards the attainment of South African national priorities. This meant striving to do research that is transformative, evidence-based, innovative, relevant and supportive of these priorities and responsibilities.

Shayne was a true academic and was playing an important role in helping to change the face of academia in South Africa to one that better reflects its demographics. Shayne was really doing well in all aspects of his life and was always respected and wellliked by his colleagues. He will be sorely missed. He is survived by his father, Ernest Jacobs, wife, Monean Jacobs, daughters Kim and Danel and grandson Liam.

Publisher's Note Springer Nature remains neutral with regard to jurisdictional claims in published maps and institutional affiliations. 